Review

\title{
Vascular Endothelial Growth Factor: An Overview Across Multiple Disease Conditions
}

\author{
Miriam Canavese \\ Department of Life Sciences, Imperial College London, SW2AZ London, United Kingdom \\ Department of Experimental Medicine, University of Perugia, Italy
}

Article history

Received: 23-02-2015

Revised: 28-03-2015

Accepted: 17-04-2015

\begin{abstract}
Vascular Endothelial Growth Factor (VEGF) is the major player in the regulation of physiological angiogenesis as well as it has also been implicated in pathological angiogenesis, associated with cancers and other conditions, among which psoriasis, autoimmune diseases and visual loss in macular degeneration. Interestingly, three regulatory Single Nucleotide Polymorphisms (rSNPs) in the promoter region of VEGF-A gene have been significantly associated with different human diseases and it is possible that, in the near future, the cumulative effect of several high-risk Single Nucleotide Polymorphisms (SNPs) may prove useful in a clinical setting. Currently, new VEGF inhibitors are undergoing clinical testing in various disease conditions, given that VEGF inhibition has also been contemplated as a possible strategy for prevention of angiogenesis and vascular leakage to decrease inflammation. This review focuses mainly on the role of Vascular Endothelial Growth Factor in several pathological contexts, highlighting the emerging association of the most common VEGF polymorphisms with disease risk. An update on the therapeutic implications of VEGF has also been documented.
\end{abstract}

Keywords: Vascular Endothelial Growth Factor (VEGF), Angiogenesis, Inflammation, VEGF Polymorphisms, Regulatory Single Nucleotide Polymorphisms (rSNPs), Single Nucleotide Polymorphisms (SNPs), VEGF Inhibitors

\section{Introduction}

For over a decade, the role of Vascular Endothelial Growth Factor (VEGF) in the regulation of angiogenesis was the object of intense investigation (Ferrara et al., 2003b). Recent evidence indicates that new vessels growth and maturation are highly complex and coordinated processes, requiring the sequential activation of a series of receptors by numerous ligands (Ferrara, 2002) and VEGF signaling often represents a critical rate-limiting step in physiological angiogenesis (Ferrara, 2004). However, more recently, vascular endothelial growth factors have been shown to also play a role in atherosclerosis, arteriogenesis, cerebral edema, neuroprotection, neurogenesis, post-ischemic brain and vessel repair and to mediate the effects of transplanted stem cells in experimental stroke (Lee et al., 2007; Greenberg and Jin, 2013).

Angiogenesis, the formation of new blood vessels from a pre-existing vascular bed, is a common component in physiological conditions as well as in several pathogenic mechanisms including cancer (Ferrara, 2002), inflammatory joint disease (Brenchley, 2000) and psoriasis (Detmar et al., 1994). VEGF is well established as a primary mediator of pathological angiogenesis (Ferrara and Davis-Smyth, 1997; Ferrara, 2004); the first cytokine identified within the VEGF family was originally referred to as vascular permeability factor (Crawshaw et al., 2012) and it is now more commonly named VEGF-A. It functions as a selective endothelial mitogen as well as regulator of increasing permeability of the vasculature (Canavese et al., 2010; Ferrara et al., 2003b). VEGF also influences the immune system by promoting monocyte activation and chemotaxis (Clauss et al., 1990). VEGF ligands exert their effects on cells by binding to specific receptor tyrosine kinases (VEGFRs) VEGFR-1 and VEGFR-2 (Ferrara et al., 2003b; Hasan and Jayson, 2001). It is through binding with these VEGFRs that VEGF exerts its effects on vascular endothelium and peripheral monocytes (Crawshaw et al., 2012). 
In the early ninety, important advances have been made regarding the biological role of VEGF. It was discovered that VEGF is expressed in spatial and temporal association with physiological events of angiogenesis in vivo (Neufeld et al., 1999). Inhibition of VEGF activity by neutralizing antibodies or by the introduction of dominant negative VEGF receptors into endothelial cells of tumour-associated blood vessels resulted in the inhibition of tumour growth and in tumour regression, indicating that VEGF is a major initiator of tumour angiogenesis (Kim et al., 1993; Millauer et al., 1994). Furthermore, it was found that VEGF expression is potentiated by hypoxia and that the potentiation of VEGF production in hypoxic areas, (e.g.: in solid tumours), contributes significantly to VEGF-driven tumour angiogenesis (Plate et al., 1992; Neufeld et al., 1999). Moreover, VEGF-induced angiogenesis was also found to play an important role in the a etiology of several additional diseases (Canavese et al., 2010; Detmar et al., 1994; Medana et al., 2010), some of them associated with abnormal angiogenesis (Aiello et al., 1994) and wound repair (Brown et al., 1992).

Finally, Vascular Endothelial Growth Factor can not only promote angiogenesis, but may also exert certain effects to alter the rate of atherosclerotic plaque development (Celletti et al., 2001). Recently, it has been demonstrated an association between VEGF promoter polymorphisms and a vast number of diseases (Buroker, 2014; Prakash et al., 2015; Che et al., 2015; Kapahi et al., 2015; Fauser and Lambrou, 2014; Tie et al., 2014; Gora-Tybor et al., 2015; Vajtr et al., 2014; Sun et al., 2014; Qi et al., 2014). This has led to investigate whether VEGF could represent a potential early disease biomarker (Canavese and Schauber 2011; Canavese and Spaccapelo, 2014) and to evaluate its role in predicting treatment response to anti-angiogenic therapy, particularly in cancer patients (Otrock et al., 2011).

This paper mainly focuses on the role of VEGF across multiple disease conditions, both reviewing the emerging association of most common VEGF polymorphisms with disease susceptibility and giving an up-date on the clinical advances in the development of novel VEGF inhibitors, as possible therapeutic intervention.

\section{Biology of VEGF and its Role in Pathologic Conditions}

Vascular Endothelial Growth Factor (VEGF) had been characterized as a heparin binding angiogenic growth factor displaying high specificity for Endothelial Cells (ECs) (Gospodarowicz et al., 1989). During embryogenesis, VEGF promotes differentiation and proliferation of ECs and the formation of immature vessels. Then, Angiopoietin-1 induces the remodelling and stabilization of blood vessels, which involves interaction with the extracellular matrix (Bisht et al., 2010).

VEGF (referred to also as VEGF-A) belongs to a gene family that includes Placental Growth Factor (PLGF), VEGF-B, VEGF-C and VEGF-D. VEGF-A is a key regulator of blood vessel growth. VEGF-C and VEGF-D regulate lymphatic angiogenesis (Karkkainen et al., 2002), emphasizing the unique role of this family in controlling growth and differentiation of multiple anatomic components of the vascular system (Ferrara et al., 2003b). Initially, VEGF binding sites were identified on the cell surface of vascular ECs in vitro and in vivo. Subsequently, it became apparent that receptors for VEGF also occur on bone marrowderived cells (Ferrara and Davis-Smyth, 1997). VEGF binds two related Receptor Tyrosine Kinases (RTKs), VEGFR-1 and VEGFR-2. Both have seven immunoglobulin-like domains in the extracellular domain, a single transmembrane region and a consensus tyrosine kinase sequence that is interrupted by a kinaseinsert domain (Terman et al., 1991). A member of the same family of RTKs is VEGFR-3 (Pajusola et al., 1992), which, however, is not a receptor for VEGF-A, but instead binds VEGF-C and VEGF-D (Karkkainen et al., 2002; Ferrara, 2004). In addition to these RTKs, VEGF interacts with a family of co-receptors, the neuropilins (Ferrara et al., 2003b).

A well-documented in vitro activity of VEGF is the ability to promote growth of vascular endothelial cells derived from arteries, veins and lympathics (Ferrara et al., 2003b).

Blood vessels proliferate by sprouting from existing vessels (angiogenesis) in inflammatory diseases, tumors and many other chronic conditions. Changes in newly formed and remodelled blood vessels are diseasespecific, as they reflect vascular adaptations to environmental cues unique to each condition. Remodelling of ECs into a venular phenotype, typical of sustained inflammation, is accompanied by expression molecules that promote endothelial gap formation and leukocyte rolling, attachment and migration. Blood vessels in tumors differ from those in inflammation. Endothelial cells in tumors undergo disorganized sprouting, proliferation and regression and become dependent on VEGF for survival (Mc Donald, 2008). The physiological activity of VEGF as survival factor for ECs has been demonstrated both in vitro and in vivo (Gerber et al., 1998a; 1998b).

VEGF has also effects on bone marrow-derived cells. It promotes monocyte chemotaxis (Clauss et al., 1990) and induces colony formation by mature subsets of granulocyte-macrophages progenitor cells (Broxmeyer et al., 1995). VEGF delivery to adult mice inhibits dendritic cell development and increases 
production of B cells and generation of myeloid cells (Gabrilovich et al., 1996; Hattori et al., 2001). It is known also as vascular permeability factor, based on its ability to induce vascular leakage (Senger et al., 1983; Dvorak et al., 1995). It is well established that such permeability-enhancing activity underlies significant roles of this molecule in inflammation and other pathological circumstances (Ferrara et al., 2003b). To this end, in situ hybridization studies have shown that VEGF mRNA is up-regulated in many human tumours (Ferrara and Davis-Smyth, 1997; Dvorak et al., 1995), so that VEGF inhibitors may be effective for treatment of haematological malignancies and several clinical trials are currently testing this hypothesis (Ferrara et al., 2003b).

Diabetes mellitus, occlusion of the central retinal vein or prematurity with subsequent exposure to oxygen can all be associated with intraocular neovascularization, which may result in vitreous haemorrhages, retinal detachment, neovascular glaucoma and blindness. All of these conditions are associated with retinal ischemia. An increase in VEGF in the aqueous and vitreous humor of the eyes, with proliferative retinopathy secondary to diabetes and other conditions have been previously described (Aiello et al., 1994; Malecaze et al., 1994). Subsequent animal studies using various VEGF inhibitors have directly shown the role of VEGF as a mediator of ischemia-induced intraocular neovascularization (Aiello et al., 1995; Adamis et al., 1996).

VEGF has also been implicated in various inflammatory disorders (Dvorak et al., 1995). It is strongly expressed by epidermal keratinocytes in wound healing and psoriasis, conditions that are characterized by increased microvascular permeability and angiogenesis (Detmar et al., 1995; Canavese et al., 2011; Crawshaw et al., 2012). Transgenic expression of VEGF in the skin results in increased density of tortuous cutaneous blood capillaries and enhanced leukocyte rolling and adhesion in post-capillary skin venules, suggesting that overexpression of VEGF in the epidermis is sufficient to induce features of chronic skin inflammation (Canavese et al., 2011; Xia et al., 2003). Notably, no changes in lymphatic vessels were detected in these studies (Detmar et al., 1998).

VEGF up-regulation has also been implicated in the development of brain edema. Enhanced levels of VEGF and its receptors have been reported in the rat brain after induction of focal cerebral ischemia (Kovacs et al., 1996). Van Bruggen et al. (1999) have shown that VEGF antagonism has beneficial effects in a mouse model of cortical ischemia, resulting in a significant reduction in the volume of edematous tissue, shortly after the onset of ischemia and in the infarct size, measured several weeks later. Additionally, VEGF has been found overexpressed in brains of cerebral malaria patients (Medana et al., 2010; Furuta et al., 2010), although, its protective or pathogenic role is still controversial (Canavese and Spaccapelo, 2014).

Hyperplasia and hypervascularity are features of polycystic ovary syndrome, a leading cause of infertility (Ferrara et al., 2003b). Several studies suggest that VEGF and Endocrine Gland-Derived Vascular Endothelial Growth Factor (EG-VEGF) may cooperate in the induction of angiogenesis in this condition (Ferrara et al., 2003a). Angiogenesis is also important in the pathogenesis of endometriosis, a condition characterized by ectopic endometrial implants in the peritoneal cavity. Large amounts of VEGF have been measured in the peritoneal fluid of patients with endometriosis (McLaren et al., 1996). According to the literatures, circulating levels of soluble VEGFR-1 derived from the placenta are increased in preeclampsia, resulting in reduced free VEGF and Placental Growth Factor (PGF). Thus, endothelial dysfunction of pre-eclampsia may be a result of excess VEGF or PGF neutralization by circulating soluble VEGFR-1 (Maynard et al., 2003; Ferrara, 2004).

\section{Association of VEGF Polymorphisms with Disease Risk}

Single nucleotide changes that affect gene expression by impacting gene regulatory sequences, such as promoters, enhances and silencers are known as regulatory Single Nucleotide Polymorphisms (rSNPs). A rSNP within a Transcriptional Factor Binding Site (TFBS) can change a transcriptional factor's (TF's) ability to bind to its TFBS, in which case the TF would be unable to effectively regulate its target gene (Buroker, 2014).

Very recently, three rSNPs in the promoter region of VEGF-A gene have been significantly associated with several human diseases or conditions. The rSNP alleles alter the TFBS in non-coding regulatory regions of the gene, which in turn can result in human disease development (Buroker, 2014). Very recently, Buroker has reported on several cases of diseases that have been listed along with the VEGF-A rSNP genotypes and allele frequencies for ill patients versus their controls (Buroker, 2014). As an example, the rs2010963 VEGFA-G allele has been found to significantly increase in patients with severe ischemic complications in Giant Cell Arteritis (GCA) (Rueda et al., 2005). This allele generates the potential SP1 binding site, where SP1 can activate or repress transcription in response to physiological and pathological stimuli (Buroker, 2014). As well as the rs1570360 VEGFA-G allele was significantly increased in patients with Sporadic Alzheimer Disease (SAD) (Yuan et al., 2009). This allele generates the potential KLF4 and MIZF binding sites, where KLF4 acts as both an activator and repressor 
and MIZF plays a role in DNA methylation and transcription repression. The proteins from these genes are individually capable of activating transcription and replication (Buroker, 2014).

Table 1 is summarizing some of the most recently found associations of VEGF polymorphisms with different human diseases.

The contribution of genetic polymorphisms in the VEGF gene to disease risk is still a controversial topic, since further epidemiological studies should investigate interaction among multiple genotypes, different ethnic groups and environmental exposure to better correlate the VEGF polymorphism with the disease susceptibility.

Interestingly, in a very recent work Fauser and colleagues evaluated a meta-analysis that demonstrated that SNPs within VEGF-A (the presence of a Cnucleotide in rs833061 or TT in rs1413711) may be associated with Age-Related Macular Degeneration (AMD) pathogenesis (Fauser and Lambrou, 2014; Huang et al., 2013). Given that VEGF SNPs are involved in disease pathogenesis and that the highly successful anti-VEGF neovascular-AMD (nAMD) therapies target VEGF-A, SNPs within VEGF-A were considered to be the most likely to predict how a patient with nAMD will respond to such therapies. The SNPs analyzed for this purpose fall into two broad categories. The first comprises SNPs within genes originally associated with AMD pathogenesis, termed AMD-related SNPs. The second category includes those SNPs specifically associated with the VEGF signaling pathway targeted by anti-VEGF therapies which are collectively termed pharmacologically related SNPs. A total of 17 VEGF-A SNPs were investigated, but only four (rs699947, rs1413711, rs699946 and rs3025000) correlated with patient response to antiVEGF therapy (Fauser and Lambrou, 2014). However, the correlation between nAMD treatment response and the VEGF SNP rs1413711 remain still under debate. The genotypes of rs1413711 were found to be indicators of anti-VEGF response in a UK study by McKibbin group (McKibbin et al., 2012), but other studies did not find this to be the case (Boltz et al., 2012; Yuan et al., 2013; Fauser and Lambrou, 2014). In the UK study, the presence of a $\mathrm{C}$ nucleotide at rs1413711 was associated with a marked improvement in visual acuity (McKibbin et al., 2012) and it had a maximum followup time of six months, whereas some of the other studies had longer durations. It is then possible that there is a statistically significant effect at month six of treatment, which decreases to a non-significant level by month twelve or month fifteen (Fauser and Lambrou, 2014). Therefore, duration of treatments may need to be taken into account in the definition of responsiveness used in each of the trials. Additionally, patients characteristics, such as the ethnic background, play an important role in nAMD development and progression (Klein et al., 2004), however, no association between patient ethnicity and genetic factors predictive of treatment response were identified in the studies reviewed by (Fauser and Lambrou, 2014).

Table 1. Association between VEGF-A gene polymorphisms and disease susceptibility

\begin{tabular}{|c|c|c|}
\hline Disease/condition & VEGF-A polymorphisms (SNPs) & Reference \\
\hline Psoriasis & $+405 \mathrm{C}>\mathrm{G} ;-460 \mathrm{~T}>\mathrm{C} ;-2578 \mathrm{C}>\mathrm{A} ;-1154 \mathrm{G}>\mathrm{A}$ & Qi et al. (2014) \\
\hline Acute renal allograft rejection & $-2578 \mathrm{C}>\mathrm{A} ;-2549 \mathrm{Ins}>\mathrm{Del} ;-1154 \mathrm{G}>\mathrm{A} ;+936 \mathrm{C}>\mathrm{T}$ & Prakash et al. (2015) \\
\hline Autoimmune diseases & $-1154 \mathrm{G}>\mathrm{A} ;+405 \mathrm{G}>\mathrm{C} ;-2578 \mathrm{C}>\mathrm{A} ;+936 \mathrm{C}>\mathrm{T} ;-460 \mathrm{~T}>\mathrm{C}$ & Che et al. (2015) \\
\hline Breast cancer & $-2578 \mathrm{C}>\mathrm{A} ;-2549 \mathrm{I}>\mathrm{D} ;-460 \mathrm{~T}>\mathrm{C} ;-7 \mathrm{C}>\mathrm{T}$ & Kapahi et al. (2015) \\
\hline Osteosarcoma & $-2578 \mathrm{C}>\mathrm{A} ;-1156 \mathrm{G}>\mathrm{A} ;+1612 \mathrm{G}>\mathrm{A} ;+936 \mathrm{C}>\mathrm{T}$ & Tie et al. (2014) \\
\hline Chronic lymphocytic leukemia & $+405 \mathrm{G}>\mathrm{C} ;+936 \mathrm{C}>\mathrm{T} ;-271 \mathrm{G}>\mathrm{A} ;+1719 \mathrm{~A}>\mathrm{T}$ & Gora-Tybor et al. (2015) \\
\hline Cervical cancer & $-2578 \mathrm{C}>\mathrm{A}(\mathrm{rs} 699947) ;-1154 \mathrm{G}>\mathrm{A}(\mathrm{rs} 1570360)$ & Zidi (2014) \\
\hline Renal cell carcinoma & $-2578 \mathrm{C}>\mathrm{A} ;-634 \mathrm{G}>\mathrm{C}$ & Zhong et al. (2014) \\
\hline $\begin{array}{l}\text { Diabetic nephropathy in } \\
\text { patients with diabetes mellitus }\end{array}$ & rs2010963; rs3025039 & Sun et al. (2014) \\
\hline $\begin{array}{l}\text { Neovascular age-related } \\
\text { macular degeneration }\end{array}$ & rs699947; $-2578 \mathrm{C}>\mathrm{A} ;+405 \mathrm{G}>\mathrm{C}+936 \mathrm{C}>\mathrm{T}$ & $\begin{array}{l}\text { Habibi et al. (2014) } \\
\text { Fauser and Lambrou (2014) }\end{array}$ \\
\hline $\begin{array}{l}\text { Myocardial infarction in patients } \\
\text { with type } 2 \text { diabetes mellitus }\end{array}$ & $-604 \mathrm{~T}>\mathrm{C}(\mathrm{rs} 2071559)$ & Kariz and Petrovic (2014) \\
\hline Endometriosis & $-1154 \mathrm{G}>\mathrm{A}$ & Perini et al. (2014) \\
\hline $\begin{array}{l}\text { Acute chest syndrome in pediatric } \\
\text { patients with sickle cell disease }\end{array}$ & $-583 \mathrm{C}>\mathrm{T}$ & Redha et al. (2014) \\
\hline Alzheimer's disease & $-2578 \mathrm{C}>\mathrm{A} ;-1154 \mathrm{G}>\mathrm{A}$ & He et al. (2013) \\
\hline Idiopathic Parkinson's disease & $-2578 \mathrm{C}>\mathrm{A} ;-634 \mathrm{C}>\mathrm{G} ; 936 \mathrm{C}>\mathrm{T}$ & Mihci et al. (2011) \\
\hline
\end{tabular}

rSNPs: Regulatory Single Nucleotide Polymorphisms

A number of human conditions have significantly been associated with VEGF-A rSNPs. Table 1 summarizes the most recent studies investigating the contribution of VEGF polymorphisms as risk factors for the development of several human diseases 
Table 2. Therapeutic implications of VEGF

\begin{tabular}{|c|c|c|c|}
\hline Disease & $\begin{array}{l}\text { Therapeutic approach } \\
\text { currently implemented }\end{array}$ & Clinical phase & Reference \\
\hline $\begin{array}{l}\text { Advanced non small cell lung cancer/ } \\
\text { Colon rectal cancer/Renal cell cancer }\end{array}$ & Bevacizumab & Approved & Sullivan and Brekken (2010) \\
\hline $\begin{array}{l}\text { Neovascular Age-related } \\
\text { Macular Degeneration (AMD) }\end{array}$ & Bevacizumab & N/A (Investigational) & Avery et al. (2006) \\
\hline Psoriasis & Bevacizumab & N/A (Investigational) & Akman et al. (2009) \\
\hline Psoriasis & Ramucirumab & N/A (Investigational) & Halin et al. (2008) \\
\hline Gastric cancer/Lung carcinomas & Ramucirumab & Approved & Aprile et al. (2013; Spratlin et al., 2010) \\
\hline Metastatic renal carcinoma & Ramucirumab & Phase II Clinical trial & Garcia et al. (2014) \\
\hline Hepatocellular carcinoma & Sorafenib & Approved & Llovet et al. (2008) \\
\hline Advanced renal cell cancer & Sorafenib & Phase III Clinical trial (TARGET) & Escudier et al. (2007) \\
\hline $\begin{array}{l}\text { Advanced non small cell lung } \\
\text { cancer/Renal cell cancer/Soft tissue } \\
\text { sarcoma/gynecological tumors }\end{array}$ & Pazopanib & Phase III Clinical trial & Sternberg et al. (2009) \\
\hline Metastaic colorectal cancer & Cediranib & Phase III Clinical trial (HORIZON) & Robertson et al. (2009) \\
\hline Metastatic colorectal cancer & IMC-1C11 & Phase I Clinical trial & Fontanella et al. (2014) \\
\hline Advanced non small cell lung cancer & Vendetanib Vs Gefitinib & Phase II trial (Investigational) & Natale et al. (2009) \\
\hline $\begin{array}{l}\text { Locally advanced or metastatic } \\
\text { non-small cell lung cancer }\end{array}$ & $\begin{array}{l}\text { Vendetanib + Docetaxel } \\
+ \text { Pemetrexed }\end{array}$ & $\begin{array}{l}\text { Phase III trial } \\
\text { (ZODIAC and ZEAL) }\end{array}$ & Morabito et al. (2009) \\
\hline $\begin{array}{l}\text { Cytokine-refractory } \\
\text { metastatic renal cell cancer }\end{array}$ & Axitinib & Phase II trial (Investigational) & Rixe et al. (2007) \\
\hline
\end{tabular}

Table 2 summarizes the therapeutic implications of VEGF, giving an overview of the clinical advances of VEGF inhibitors development across multiple disease conditions

Theoretically, SNP variants could affect the severity of the disease to different degrees: Some variants may, e.g., increase inflammation more than others. Expression of different variants could therefore explain differences between study findings; this would be difficult to confirm in a clinical setting, however, as the variants may have relatively little effect. Overall, to date it appears that these AMD-related SNPs are of limited clinical value as predictors of individual patient response to anti-VEGF treatment (Fauser and Lambrou, 2014).

The categorization of the identified SNPs into the two above groups, AMD-related and pharmacologically related SNPs, revealed that the more widely studied AMD-related SNPs have yet to provide a substantiated clinical predictive value (Hagstrom et al., 2013). AntiVEGF-related SNPs have not yet accumulated the same amount of evidence as AMD-related SNPs either to commend or reject them as potentially useful biomarkers. One of the more promising SNPs is VEGFA rs699947, but because of the variability of the study results to date, it is still difficult to prove it as a useful biomarker. Thanks to the ongoing investigations into the genetics of AMD (Fritsche et al., 2013) and the full realization of the efficacy of antiVEGF treatments, other candidate SNPs may yet emerge. Clinical factors, such as patient baseline characteristics, also show potential as predictive markers of the treatment response (Finger et al., 2014; van Asten et al., 2014). It may be possible that the cumulative analysis of several high-risk AMD genes could result in the identification of patients with specific response patterns to anti-VEGF treatment (Investigators et al., 2012), as van Asten and colleagues showed in a recently published study (van Asten et al., 2014).

\section{Therapeutic Implications and Updates on the Clinical Advances of VEGF Inhibitors Development}

The VEGF family clearly plays an essential role in the regulation of embryonic and postnatal physiological angiogenesis processes, such as normal growth processes (Gerber et al., 1999b; 1999a) and cyclical ovarian function (Ferrara et al., 1998). Furthermore, many studies have documented acute neuro-protective effects of VEGF in experimental stroke (Zhang et al., 2000; Hayashi et al., 1998; Sun et al., 2003; Wang et al., 2006; Feng et al., 2008; Zheng et al., 2010; Sun et al., 2004), as well as, other reports have described long term VEGF-mediated beneficial effects of stem cell treatment (Lee et al., 2007; Chu et al., 2005; Zhu et al., 2005; Harms et al., 2010; Horie et al., 2011).

The hypothesis that therapeutic angiogenesis may be beneficial for disorders characterized by inadequate tissue perfusion generated a high level of enthusiasm in the field of cardiovascular medicine and led to many clinical trials (Ferrara, 2004). Early studies have shown that VEGF administration leads to a recovery of normal endothelial reactivity in dysfunctional endothelium (Bauters et al., 1995). Furthermore, VEGF gene transfer was also reported to prevent the ischemic peripheral neuropathy associated with lower extremity vascular insufficiency in a rabbit model (Schratzberger et al., 2000).

The idea that VEGF may result in therapeutically significant angiogenesis in humans was initially tested 
by (Isner et al., 1996) using a gene therapy approach. However, a greater understanding of the differential role of VEGF receptors had opened additional avenues. In particular, several studies have emphasized that VEGFR-1 possesses important activities in hematopoiesis and in the recruitment of mononuclear cells. The fact that VEGFR-1 activation is associated with fewer side effects relative to VEGF made it a particularly attractive target. Furthermore, the report that a VEGFR-1 agonist protected the liver from toxic damage, by instructing the quiescent endothelium to produce a series of tissue-specific growth factors, extended the potential clinical applications of VEGFR-1 agonists (LeCouter et al., 2003). Other activities of VEGF may have interesting clinical implications. For example, on the basis of the key role played by VEGF in angiogenesis and endochondral bone formation, the application of this factor might be useful to enhance revascularization and healing of fractures and other skeletal conditions (Carano and Filvaroff, 2003). Several studies have shown that both recombinant (Street et al., 2002) and adenovirus-delivered-VEGF leads to enhanced blood vessel formation and ossification in models of bone damage (Tarkka et al., 2003).

On the other hand, already in 1971 Folkman and colleagues started initial efforts aimed to isolate a tumor angiogenesis factor from human and animal cancers (Folkman et al., 1971; Folkman, 1971). Therefore it became clear that VEGF blockage inhibits pathological angiogenesis in a wide variety of tumour models, a phenomenon that has led to the clinical development of a vast number of VEGF inhibitors (Ferrara et al., 2003b). Inhibition of VEGF signaling in tumors stop sprouting angiogenesis and triggers regression of some tumor vessels while normalizing others. Some capillaries in normal thyroid, pancreatic islets and intestine may also regress after VEGF blockade, but most remodelled vessels at sites of inflammation do not. Pericytes and empty sleeves of vascular basement membrane persist after endothelial cells regress and provide a scaffold for blood vessel regrowth, which can occur within days after the inhibition ends. The clinical efficacy of VEGF signaling inhibitors in cancer provides proof of concept and stimulates the search for even more effective agents (Mc Donald, 2008).

The potential clinical usefulness of VEGF inhibition is not limited to cancer. Phase 3 trials in AMD patients are under way. As already noted, gynaecologic conditions such as endometriosis or polycystic ovary syndrome might also benefit from this treatments (Ferrara et al., 2003b), as well as VEGF antagonists have been recently proposed for the treatment of psoriasis (Crawshaw et al., 2012).
Indeed, it is conceivable that non-neoplastic conditions will show a greater clinical response, given the reduced likelihood of non-transformed cells to activate alternative angiogenic pathways and thus develop resistance (Ferrara et al., 2003b).

As summarized in Table 2, over the last decade, a number of monoclonal antibodies and small molecules that specifically target the VEGF pathway have been studied as single agents or in combination with chemotherapies (Sullivan and Brekken, 2010; Fontanella et al., 2014). Bevacizumab, for example, is a monoclonal antibody (mAb) that binds VEGF and it has gained worldwide approval for first or second line treatment in several different tumour types (Sullivan and Brekken, 2010) AMD (Avery et al., 2006) and in psoriasis (Akman et al., 2009). Recent studies indicates VEGFR-2 as a novel target (Lu et al., 2002): Biological and preclinical evidence suggests that blockage of VEGFR-2 could be a promising strategy both to inhibit tumor-induced angiogenesis (Hamerlik et al., 2012; Witte et al., 1998) and to control psoriasis (Halin et al., 2008). In order to proof this hypothesis a novel human IgG1 mAb that specifically blocks the VEGFR2, named Ramucirumab, was developed and it has produced notable results in different diseases including gastric cancers and lung carcinomas (Aprile et al., 2013; Spratlin et al., 2010). In these poor prognosis diseases, even a small absolute survival benefit of two months is clinically valuable. Disappointing clinical results reported for the ROSE study confirm that breast cancer may limitedly benefit from angiogenic inhibitors (Mackey et al., 2014). While ongoing studies will clarify the role of ramucirumab in metastatic colorectal cancer, translational research will provide more details about how to properly select optimal candidates and corroborate the ethnical difference in benefit. Despite huge efforts have been made to identify a predictive biomarker, no validated predictor is currently available for selecting optimal candidates to antiangiogenic therapy or monitoring treatment response. Future research will possibly increase our knowledge on how to select patients who are more likely to be responsive to antiangiogenic treatment. As well, the role of VEGF in reverting immunosuppression should also be better elucidated. Moreover, novel oral VEGFR-2 inhibitors will possibly add some value to this strategy (Fontanella et al., 2014).

\section{Conclusive Remarks}

Angiogenesis is an important biological process not only under physiological conditions, but also in a variety of diseases, including cancer, diabetic retinopathy, rheumatoid arthritis, AMD, stroke, psoriasis and others (Risau, 1997). The research conducted after 
the discovery of VEGF revealed that it is a central regulator of angiogenesis and vasculogenesis. This has consequently led to the development of drugs aimed at the treatment of pathological conditions associated with angiogenic disorders. A high probability of benefit is desirable to justify the choice of anti-angiogenic therapy from an ever-expanding list of expensive new anti-cancer agents. Still, biomarkers of response to antiangiogenic agents are inconclusive for predicting benefit from these drugs. The contribution of genetic polymorphisms in the VEGF gene to disease risk is still controversial. However, there are several types of genetic variations found within the genome that can act as biomarkers, but single nucleotide polymorphisms are the most common, with over 19 million within the human genome (Wang et al., 2012). SNPs are usually found in non-coding-regions and can be used as markers to locate genes associated with disease or drug response. Therefore, it is possible that, in the near future, the combined effect of high-risk SNPs may be beneficial in a clinical setting and that other genetic biomarkers may emerge.

\section{Acknowledgment}

Dr. Canavese has received funding from the European Union Seventh Framework Programme (FP7/2007-2013) under the MARIE CURIE COFUNDING OF REGIONAL, NATIONAL AND INTERNATIONAL PROGRAMME I-MOVE grant agreement $n^{\circ} 267232$.

\section{Disclosure}

The author has no financial interests to disclose.

\section{References}

Adamis, A.P., D.T. Shima, M.J. Tolentino, E.S. Gragoudas and N. Ferrara et al., 1996. Inhibition of vascular endothelial growth factor prevents retinal ischemia-associated iris neovascularization in a nonhuman primate. Arch Ophthalmol, 114: 66-71. PMID: 8540853

Aiello, L.P., R.L. Avery, P.G. Arrigg, B.A. Keyt and H.D. Jampel et al., 1994. Vascular endothelial growth factor in ocular fluid of patients with diabetic retinopathy and other retinal disorders. N Engl. J. Med., 331: 1480-1487. DOI: 10.1056/NEJM199412013312203

Aiello, L.P., E.A. Pierce, E.D. Foley, H. Takagi and H. Chen et al., 1995. Suppression of retinal neovascularization in vivo by inhibition of Vascular Endothelial Growth Factor (VEGF) using soluble VEGF-receptor chimeric proteins. Proc. Natl. Acad. Sci. USA, 92: 10457-10461. PMID: 7479819
Akman, A., E. Yilmaz, H. Mutlu and M. Ozdogan, 2009. Complete remission of psoriasis following bevacizumab therapy for colon cancer. Clin. Exp. Dermatol., 34: e202-204. DOI: 10.4103/0019-5154.143574

Aprile, G., M. Bonotto, E. Ongaro, C. Pozzo and F. Giuliani, 2013. Critical appraisal of ramucirumab (IMC-1121B) for cancer treatment: From benchside to clinical use. Drugs, 73: 2003-2015. PMID: 24277700

Avery, R.L., D.J. Pieramici, M.D. Rabena, A.A. Castellarin and M.A. Nasir et al., 2006. Intravitreal bevacizumab (Avastin) for neovascular age-related macular degeneration. Ophthalmology, 113: 363-372. PMID: 16458968

Bauters, C., T. Asahara, L.P. Zheng, S. Takeshita and S. Bunting et al., 1995. Recovery of disturbed endothelium-dependent flow in the collateralperfused rabbit ischemic hindlimb after administration of vascular endothelial growth factor. Circulation, 91: 2802-2809.

DOI: 10.1161/01.CIR.91.11.2802

Bisht, M., D.C. Dhasmana and S.S. Bist, 2010. Angiogenesis: Future of pharmacological modulation. Ind. J. Pharmacol., 42: 2-8. DOI: $10.4103 / 0253-7613.62395$

Boltz, A., M. Ruiß, J.B. Jonas, Y. Tao and F. Rensch et al., 2012. Role of vascular endothelial growth factor polymorphisms in the treatment success in patients with wet age-related macular degeneration. Ophthalmology, 119: 1615-1620. PMID: 22521084

Brenchley, P.E., 2000. Angiogenesis in inflammatory joint disease: A target for therapeutic intervention. Clin. Exp. Immunol., 121: 426-942.

DOI: $10.1046 / j .1365-2249.2000 .01299 . x$

Brown, L.F., K.T. Yeo, B. Berse, T.K. Yeo and D.R. Senger et al., 1992. Expression of vascular permeability factor (vascular endothelial growth factor) by epidermal keratinocytes during wound healing. J. Exp. Med., 176: 1375-1379. PMID: 1402682

Broxmeyer, H.E., S. Cooper, Z.H. Li, L. Lu and H.Y. Song et al., 1995. Myeloid progenitor cell regulatory effects of vascular endothelial cell growth factor. Int. J. Hematol., 62: 203-215. PMID: 8589366

Buroker, N.E., 2014. VEGFA rSNPs, transcriptional factor binding sites and human disease. J. Physiol. Sci., 64: 73-76. DOI: 10.1007/s12576-013-0293-4

Canavese, M., F. Altruda, T. Ruzicka and J. Schauber, 2010. Vascular Endothelial Growth Factor (VEGF) in the pathogenesis of psoriasis-a possible target for novel therapies? J. Dermatol. Sci., 58: 171-176. DOI: $10.1016 /$ j.jdermsci.2010.03.023

Canavese, M., F. Altruda, L. Silengo, V. Castiglioni and E. Scanziani et al., 2011. Clinical, pathological and immunological features of psoriatic-like lesions affecting keratin 14-vascular endothelial growth factor transgenic mice. Histol. Histopathol., 26: 285-296. PMID: 21210341 
Canavese, M. and J. Schauber, 2011. Vascular endothelial growth factor and psoriasis pathogenesis: Major culprit, treatment target, or possible biomarker? Adv. Psoriasis Inflammatory Skin Dis., 2: 89-94. DOI: $10.5275 /$ ijcr.2011.07.05

Canavese, M. and R. Spaccapelo, 2014. Protective or pathogenic effects of Vascular Endothelial Growth Factor (VEGF) as potential biomarker in cerebral malaria. Pathog. Glob. Health, 108: 67-75. PMID: 24601908

Carano, R.A. and E.H. Filvaroff, 2003. Angiogenesis and bone repair. Drug Discov. Today, 8: 980-989. DOI: $10.1016 / \mathrm{S} 1359-6446(03) 02866-6$

Celletti, F.L., J.M. Waugh, P.G. Amabile, A. Brendolan and P.R. Hilfiker et al., 2001. Vascular endothelial growth factor enhances atherosclerotic plaque progression. Nat. Med., 7: 425-429.

Che, N., Y. Li, S. Liu, W. Pan and Y. Liu, 2015. Investigation on association between five common polymorphisms in vascular endothelial growth factor and prototypes of autoimmune diseases. Immunobiology. PMID: 25641412

Chu, K., K. Park, S.T. Lee, K.H. Jung and S.Y. Ko, 2005. Combined treatment of vascular endothelial growth factor and human neural stem cells in experimental focal cerebral ischemia. Neurosci. Res., 53: 384-390. DOI: 10.1016/j.neures.2005.08.010

Clauss, M., M. Gerlach, H. Gerlach, J. Brett, F. Wang and P.C. Familletti et al., 1990. Vascular permeability factor: A tumor-derived polypeptide that induces endothelial cell and monocyte procoagulant activity and promotes monocyte migration. J. Exp. Med., 172: 1535-1545. PMID: 2258694

Crawshaw, A.A., C.E. Griffiths and H.S. Young, 2012. Investigational VEGF antagonists for psoriasis. Expert. Opin. Investig. Drugs., 21: 33-43. PMID: 22088218

Detmar, M., L.F. Brown, K.P. Claffey, K.T. Yeo and O. Kocher et al., 1994. Overexpression of vascular permeability factor/vascular endothelial growth factor and its receptors in psoriasis. J. Exp. Med., 180: 1141-1146. PMID: 8064230

Detmar, M., L.F. Brown, M.P. Schön, B.M. Elicker and P. Velasco et al., 1998. Increased microvascular density and enhanced leukocyte rolling and adhesion in the skin of VEGF transgenic mice. J. Invest. Dermatol., 111: 1-6. PMID: 9665379

Detmar, M., K.T. Yeo, J.A. Nagy, L.V. de Water and L.F. Brown, 1995. Keratinocyte-derived vascular permeability factor (vascular endothelial growth factor) is a potent mitogen for dermal microvascular endothelial cells. J. Invest. Dermatol., 105: 44-50. DOI: $10.1111 / 1523-1747 . e p 12312542$
Dvorak, H.F., L.F. Brown, M. Detmar and A.M. Dvorak, 1995. Vascular permeability factor/vascular endothelial growth factor, microvascular hyperpermeability and angiogenesis. Am. J. Pathol., 146: 1029-1039. PMCID: PMC1869291

Escudier, B., T. Eisen, W.M. Stadler, C. Szczylik and S. Oudard et al., 2007. Sorafenib in advanced clear-cell renal-cell carcinoma. N Engl. J. Med., 356: 125-134. DOI: 10.1056/NEJMoa060655

Fauser, S. and G.N. Lambrou, 2014. Genetic predictive biomarkers of anti-VEGF treatment response in patients with neovascular age-related macular degeneration. Surv. Ophthalmol., 60: 138-152. PMID: 25596882

Feng, Y., P.G. Rhodes and A.J. Bhatt, 2008. Neuroprotective effects of vascular endothelial growth factor following hypoxic ischemic brain injury in neonatal rats. Pediatr. Res., 64: 370-374. PMID: 18535483

Ferrara, N., 2002. VEGF and the quest for tumour angiogenesis factors. Nat. Rev. Cancer, 2: 795-803. PMID: 12360282

Ferrara, N., 2004. Vascular endothelial growth factor: Basic science and clinical progress. Endocr. Rev., 25: 581-611. PMID: 15294883

Ferrara, N., H. Chen, T. Davis-Smyth, H.P. Gerber and T.N. Nguyen et al., 1998. Vascular endothelial growth factor is essential for corpus luteum angiogenesis. Nat. Med., 4: 336-340.

DOI: $10.1038 / \mathrm{nm} 0398-336$

Ferrara, N. and T. Davis-Smyth, 1997. The biology of vascular endothelial growth factor. Endocr. Rev., 18: 4-25. PMID: 9034784

Ferrara, N., G. Frantz, J. LeCouter, L. Dillard-Telm and T. Pham et al., 2003a. Differential expression of the angiogenic factor genes Vascular Endothelial Growth Factor (VEGF) and endocrine gland-derived VEGF in normal and polycystic human ovaries. Am. J. Pathol., 162: 1881-1893. PMID: 12759245

Ferrara, N., H.P. Gerber and J. LeCouter, 2003b. The biology of VEGF and its receptors. Nat. Med., 9: 669-676. PMID: 12778165

Finger, R.P., S.S. Wickremasinghe, P.N. Baird and R.H. Guymer, 2014. Predictors of anti-VEGF treatment response in neovascular age-related macular degeneration. Surv. Ophthalmol., 59: 1-18. PMID: 24332379

Folkman, J., 1971. Tumor angiogenesis: Therapeutic implications. N Engl. J. Med., 285: 1182-1186. PMID: 4938153

Folkman, J., E. Merler, C. Abernathy and G. Williamsm, 1971. Isolation of a tumor factor responsible for angiogenesis. J. Exp. Med., 133: 275-288.

PMID: 4332371 
Fontanella, C., E. Ongaro, S. Bolzonello, M. Guardascione and G. Fasola et al., 2014. Clinical advances in the development of novel VEGFR2 inhibitors. Ann. Transl. Med., 2: 123-123. PMID: 25568876

Fritsche, L.G., W. Chen, M. Schu, B.L. Yaspan and Y. $\mathrm{Yu}$ et al., 2013. Seven new loci associated with age-related macular degeneration. Nat. Genet., 45: 433-439. DOI: $10.1038 / n g .2578$

Furuta, T., M. Kimura and N. Watanabe, 2010. Elevated levels of Vascular Endothelial Growth Factor (VEGF) and soluble Vascular Endothelial Growth Factor Receptor (VEGFR)-2 in human malaria. Am. J. Trop. Med. Hyg., 82: 136-139. PMID: 20065009

Gabrilovich, D.I., H.L. Chen, K.R. Girgis, H.T. Cunningham and G.M. Meny et al., 1996. Production of vascular endothelial growth factor by human tumors inhibits the functional maturation of dendritic cells. Nat. Med., 2: 1096-1103. DOI: $10.1038 / \mathrm{nm} 1096-1096$

Gerber, H.P., V. Dixit and N. Ferrara, 1998a. Vascular endothelial growth factor induces expression of the antiapoptotic proteins $\mathrm{Bcl}-2$ and $\mathrm{A} 1$ in vascular endothelial cells. J. Biol. Chem., 273: 13313-13316. PMID: 9582377

Gerber, H.P., A. McMurtrey, J. Kowalski, M. Yan and B.A. Keyt et al., 1998b. Vascular endothelial growth factor regulates endothelial cell survival through the phosphatidylinositol 3'-kinase/Akt signal transduction pathway. Requirement for Flk-1/KDR activation. J. Biol. Chem., 273: 30336-30343. DOI: $10.1074 / j b c .273 .46 .30336$

Gerber, H.P., K.J. Hillan, A.M. Ryan, J. Kowalski and G.A. Keller et al., 1999a. VEGF is required for growth and survival in neonatal mice. Development, 126: 1149-1159. PMID: 10021335

Gerber, H.P., T.H. Vu, A.M. Ryan, J. Kowalski and Z. Werb et al., 1999b. VEGF couples hypertrophic cartilage remodeling, ossification and angiogenesis during endochondral bone formation. Nat. Med., 5: 623-628. PMID: 10371499

Gora-Tybor, J., J. Szemraj, T. Robak and K. Jamroziak, 2015. Clinical relevance of vascular endothelial growth factor type A (VEGFA) and VEGF receptor type 2 (VEGFR2) gene polymorphism in chronic lymphocytic leukemia. Blood Cells Mol. Dis., 54: 139-143. PMID: 25488616

Gospodarowicz, D., J.A. Abraham and J. Schilling, 1989. Isolation and characterization of a vascular endothelial cell mitogen produced by pituitaryderived folliculo stellate cells. Proc. Natl. Acad. Sci. USA, 86: 7311-7315. PMID: 2798412

Greenberg, D.A. and K. Jin, 2013. Vascular Endothelial Growth Factors (VEGFs) and stroke. Cell Mol. Life Sci., 70: 1753-1761.

DOI: $10.1007 / \mathrm{s} 00018-013-1282-8$
Garcia, J.A., G.R. Hudes, T.K. Choueiri, W.M. Stadler and L.S. Wood et al., 2014. A phase 2, single-arm study of ramucirumab in patients with metastatic renal cell carcinoma with disease progression on or intolerance to tyrosine kinase inhibitor therapy. Cancer, 120: 1647-1655.

Hagstrom, S.A., G.S. Ying, G.J. Pauer, G.M. SturgillShort and J. Huang et al., 2013. Pharmacogenetics for genes associated with age-related macular degeneration in the Comparison of AMD Treatments Trials (CATT). Ophthalmology, 120: 593-599. PMID: 23337555

Halin, C., H. Fahrngruber, J.G. Meingassner, G. Bold and A. Littlewood-Evans et al., 2008. Inhibition of chronic and acute skin inflammation by treatment with a vascular endothelial growth factor receptor tyrosine kinase inhibitor. Am. J. Pathol., 173: 265-277. PMID: 18535184

Hamerlik, P., J.D. Lathia, R. Rasmussen, Q. Wu and J. Bartkova et al., 2012. Autocrine VEGF-VEGFR2Neuropilin-1 signaling promotes glioma stem-like cell viability and tumor growth. J. Exp. Med., 209: 507-520. PMID: 22393126

Harms, K.M., L. Li and L.A. Cunningham, 2010. Murine neural stem/progenitor cells protect neurons against ischemia by HIF-1alpha-regulated VEGF signaling. PLoS One, 5: e9767-e9767. PMID: 20339541

Hasan, J. and G.C. Jayson, 2001. VEGF antagonists. Expert. Opin. Biol. Ther., 1: 703-18. PMID: 11727506

Hattori, K., S. Dias, B. Heissig, N.R. Hackett and D. Lyden et al., 2001. Vascular endothelial growth factor and angiopoietin-1 stimulate postnatal hematopoiesis by recruitment of vasculogenic and hematopoietic stem cells. J. Exp. Med., 193: 1005-1014. PMID: 11342585

Hayashi, T., K. Abe and Y. Itoyama, 1998. Reduction of ischemic damage by application of vascular endothelial growth factor in rat brain after transient ischemia. J. Cereb. Blood Flow Metab., 18: 887-895. PMID: 9701350

Horie, N., M.P. Pereira, K. Niizuma, G. Sun and H. Keren-Gill et al., 2011. Transplanted stem cellsecreted vascular endothelial growth factor effects poststroke recovery, inflammation and vascular repair. Stem. Cells, 29: 274-285. PMID: 21732485

Huang, C., Y. Xu, X. Li and W. Wang, 2013. Vascular endothelial growth factor A polymorphisms and agerelated macular degeneration: A systematic review and meta-analysis. Mol. Vis., 19: 1211-1221. PMID: 23761723

Habibi, I., I. Sfar, A. Chebil, F. Kort and R. Bouraoui, 2014. Vascular endothelial growth factor genetic polymorphisms and susceptibility to age-related macular degeneration in Tunisian population. Biomarker Res., 2: 15-15. DOI: $10.1186 / 2050-7771-2-15$ 
He, J., Q.J. Zhang, Q.F. Lin, Y.F. Chena and X.Z. Lina et al., 2013. Molecular analysis of SMN1, SMN2, NAIP, GTF2H2 and H4F5 genes in 157 Chinese patients with spinal muscular atrophy. Gene, 518: 325-329.

Investigators, I.S., U. Chakravarthy, S.P. Harding, C.A. Rogers and S.M. Downes et al., 2012. Ranibizumab versus bevacizumab to treat neovascular age-related macular degeneration: One-year findings from the IVAN randomized trial. Ophthalmology, 119: 1399-1411. PMID: 22578446

Isner, J.M., A. Pieczek, R. Schainfeld, R. Blair and L. Haley et al., 1996. Clinical evidence of angiogenesis after arterial gene transfer of phVEGF165 in patient with ischaemic limb. Lancet, 348: 370-374. PMID: 8709735

Kapahi, R., K. Guleria, V. Sambyal, M. Manjari and M. Sudan et al., 2015. Association of VEGF and VEGFR1 polymorphisms with breast cancer risk in North Indians. Tumour. Biol. PMID: 25604142

Karkkainen, M.J., T. Mäkinen and K. Alitalo, 2002. Lymphatic endothelium: A new frontier of metastasis research. Nat. Cell Biol., 4: E2-5. PMID: 11780131

Kim, K.J., B. Li, J. Winer, M. Armanini and N. Gillett et al., 1993. Inhibition of vascular endothelial growth factor-induced angiogenesis suppresses tumour growth in vivo. Nature, 362: 841-844. PMID: 7683111

Klein, R., T. Peto, A. Bird and M.R. Vannewkirk, 2004. The epidemiology of age-related macular degeneration. Am. J. Ophthalmol., 137: 486-495. PMID: 15013873

Kovacs, Z., K. Ikezaki, K. Samoto, T. Inamura and M. Fukui, 1996. VEGF and flt. Expression time kinetics in rat brain infarct. Stroke, 27: 1865-1872. PMID: 8841346

Kariz, S. and D. Petrovic, 2014. Minor association of kinase insert domain-containing receptor gene polymorphism (rs2071559) with myocardial infarction in Caucasians with type 2 diabetes mellitus: Case-control cross-sectional study. Clin. Biochem., 47: 192-196. PMID: 25128838

LeCouter, J., D.R. Moritz, B. Li, G.L. Phillips and X.H. Liang et al., 2003. Angiogenesis-independent endothelial protection of liver: Role of VEGFR-1. Science, 299: 890-893. PMID: 12574630

Lee, H.J., K.S. Kim, I.H. Park and S.U. Kim, 2007. Human neural stem cells over-expressing VEGF provide neuroprotection, angiogenesis and functional recovery in mouse stroke model. PLoS One, 2: e156-e156. PMID: 17225860

Lu, D., X. Jimenez, H. Zhang, P. Bohlen and L. Witte et al., 2002. Selection of high affinity human neutralizing antibodies to VEGFR2 from a large antibody phage display library for antiangiogenesis therapy. Int. J. Cancer, 97: 393-399.

PMID: 11774295
Llovet, J.M., S. Ricci, V. Mazzaferro, P. Hilgard and E. Gane et al., 2008. Sorafenib in advanced hepatocellular carcinoma. N Engl. J. Med., 359: 378-390. DOI: 10.1056/NEJMoa0708857

Mackey, J.R., M. Ramos-Vazquez, O. Lipatov, N. Mccarthy and D. Krasnozhon et al., 2014. Primary results of ROSE/TRIO-12, a randomized placebocontrolled phase iii trial evaluating the addition of ramucirumab to first-line docetaxel chemotherapy in metastatic breast cancer. J. Clin. Oncol.

DOI: $10.1200 / J C O .2014 .57 .1513$

Malecaze, F., S. Clamens, V., A. Mathis, P. Chollet and C. Favard et al., 1994. Detection of vascular endothelial growth factor messenger RNA and vascular endothelial growth factor-like activity in proliferative diabetic retinopathy. Arch. Ophthalmol., 112: 1476-1482. PMID: 7980139

Maynard, S.E., J.Y. Min, J. Merchan, K.H. Lim and J. Li et al., 2003. Excess placental soluble fms-like tyrosine kinase 1 (sFlt1) may contribute to endothelial dysfunction, hypertension and proteinuria in preeclampsia. J. Clin. Invest., 111: 649-658. DOI: 10.1172/JCI200317189

Mc Donald, D.M., 2008. Angiogenesis and vascular remodeling in inflammation and cancer: Biology and architecture of the vasculature. Angiogenesis.

DOI: 10.1007/978-0-387-71518-6_2

Mckibbin, M., M. Ali, S. Bansal, P.D. Baxter and K. West et al., 2012. CFH, VEGF and HTRA1 promoter genotype may influence the response to intravitreal ranibizumab therapy for neovascular agerelated macular degeneration. Br. J. Ophthalmol., 96: 208-212. PMID: 21558292

Mclaren, J., A. Prentice, D.S. Charnock-Jones, S.A. Millican and K.H. Muller et al., 1996. Vascular endothelial growth factor is produced by peritoneal fluid macrophages in endometriosis and is regulated by ovarian steroids. J. Clin. Invest, 98: 482-489. PMID: 8755660

Medana, I. M., N.P. Day, R. Roberts, N. Sachanonta and H. Turley et al., 2010. Induction of the vascular endothelial growth factor pathway in the brain of adults with fatal falciparum malaria is a non-specific response to severe disease. Histopathology, 57: 282-294. PMID: 20716170

Millauer, B., L.K. Shawver, K.H. Plate, W. Risau and A. Ullrich, 1994. Glioblastoma growth inhibited in vivo by a dominant-negative Flk-1 mutant. Nature, 367: 576-579. PMID: 8107827

Morabito, A., M.C. Piccirillo, F. Falasconi, G.D. Feo and A.D. Giudice et al., 2009. Vandetanib (ZD6474), a Dual Inhibitor of Vascular Endothelial Growth Factor Receptor (VEGFR) and Epidermal Growth Factor Receptor (EGFR) tyrosine Kinases: Current status and future directions. Oncologist, 14: 378-390. DOI: $10.1634 /$ theoncologist.2008-0261 
Mihci, E., S.S. Ozkaynaka, N. Sallakcib, F. Kizilaya and U. Yavuzerb et al., 2011. VEGF polymorphisms and serum VEGF levels in Parkinson's disease. Neurosci. Lett., 494: 1-5.

DOI: 10.1016/j.neulet.2011.02.027

Neufeld, G., T. Cohen, S. Gengrinovitch and Z. Poltorak, 1999. Vascular Endothelial Growth Factor (VEGF) and its receptors. Faseb. J., 13: 9-22. PMID: 9872925

Natale, R.B., D. Bodkin, R. Govindan, B.G. Sleckman and N.A. Rizvi et al., 2009. Vandetanib versus gefitinib in patients with advanced non-small-cell lung cancer: Results from a two-part, double-blind, randomized phase II study. J. Clin. Oncol., 27: 2523-2529. DOI: 10.1200/JCO.2008.18.6015

Otrock, Z.K., H.A. Hatoum, K.M. Musallam, A.H. Awada and A.I. Shamseddine, 2011. Is VEGF a predictive biomarker to anti-angiogenic therapy? Crit. Rev. Oncol. Hematol., 79: 103-111.

DOI: 10.1016/j.critrevonc.2010.07.008

Pajusola, K., O. Aprelikova, J. Korhonen, A. Kaipainen and L. Pertovaara et al., 1992. FLT4 receptor tyrosine kinase contains seven immunoglobulin-like loops and is expressed in multiple human tissues and cell lines. Cancer Res., 52: 5738-5743.

DOI: 10.1016/j.critrevonc.2010.07.008

Plate, K.H., G. Breier, H.A. Weich and W. Risau, 1992. Vascular endothelial growth factor is a potential tumour angiogenesis factor in human gliomas in vivo. Nature, 359: 845-848. PMID: 1279432

Perini, J.A., J.V. Cardoso, P.T. Berardo, R. Vianna-Jorge and L.E. Nasciutti et al., 2014. Role of vascular endothelial growth factor polymorphisms ($2578 C>A,-460 T>C,-1154 G>A,+405 G>C$ and $+936 C>T$ ) in endometriosis: A case-control study with Brazilians. BMC Women's Health, 14: 117-117. DOI: 10.1186/1472-6874-14-117

Prakash, S., S. Agrawal, S. Kumar and N. Prasad, 2015. Impact of vascular endothelial growth factor single nucleotide polymorphism association on acute renal allograft rejection. Nephron., 129: 91-96. PMID: 25659610

Qi, M., X. Huang, L. Zhou and J. Zhang, 2014. Four polymorphisms of VEGF $(+405 \mathrm{C}>\mathrm{G},-460 \mathrm{~T}>\mathrm{C}$, $2578 \mathrm{C}>\mathrm{A}$ and $-1154 \mathrm{G}>\mathrm{A}$ ) in susceptibility to psoriasis: A meta-analysis. DNA Cell Biol., 33: 234-244.

Risau, W., 1997. Mechanisms of angiogenesis. Nature, 386: 671-674. PMID: 9109485

Rueda, B., M.A. Lopez-Nevot, M.J. Lopez-Diaz, C. Garcia-Porrua and J. Martin et al., 2005. A functional variant of vascular endothelial growth factor is associated with severe ischemic complications in giant cell arteritis. J. Rheumatol., 32: 1737-1741. PMID: 16142870
Redha, N.A., N. Mahdi, H.H. Al-Habboubi and W.Y. Almawi, 2014. Impact of VEGFA-583C $>\mathrm{T}$ polymorphism on serum VEGF levels and the susceptibility to acute chest syndrome in pediatric patients with sickle cell disease. Pediatric Blood Cancer, 61: 2310-2312.

Robertson, J.D., N.A. Botwood, M.L. Rothenberg and H.J. Schmoll, 2009. Phase III trial of FOLFOX plus bevacizumab or cediranib (AZD2171) as first-line treatment of patients with metastatic colorectal cancer: HORIZON III. Clin. Colorectal Cancer, 8: 59-60. DOI: 10.3816/CCC.2009.n.010

Rixe, O., R.M. Bukowski, M.D. Michaelson, G. Wilding and G.R. Hudes et al., 2007. Axitinib treatment in patients with cytokine-refractory metastatic renal-cell cancer: A phase II study. Lancet Oncol., 8: 975-984. DOI: $10.1016 / \mathrm{S} 1470-2045(07) 70285-1$

Schratzberger, P., G. Schratzberger, M. Silver, C. Curry and M. Kearney et al., 2000. Favorable effect of VEGF gene transfer on ischemic peripheral neuropathy. Nat. Med., 6: 405-413. PMID: 10742147

Senger, D.R., S.J. Galli, A.M. Dvorak, C.A. Perruzzi and V.S. Harvey et al., 1983. Tumor cells secrete a vascular permeability factor that promotes accumulation of ascites fluid. Science, 219: 983-985. PMID: 6823562

Spratlin, J.L., K.E. Mulder and J.R. Mackey, 2010. Ramucirumab (IMC-1121B): A novel attack on angiogenesis. Future Oncol., 6, 1085-1094. PMID: 20624120

Street, J., M. Bao, L. Deguzman, S. Bunting and F.V. Peale et al., 2002. Vascular endothelial growth factor stimulates bone repair by promoting angiogenesis and bone turnover. Proc. Natl. Acad. Sci. USA, 99: 9656-9661. DOI: 10.1073/pnas. 152324099

Sullivan, L.A. and R.A. Brekken, 2010. The VEGF family in cancer and antibody-based strategies for their inhibition. MAbs., 2: 165-175. PMID: 20190566

Sun, L., Q. Yuan, N. Cao, W. Guo and L. Yao et al., 2014. VEGF genetic polymorphisms may contribute to the risk of diabetic nephropathy in patients with diabetes mellitus: A meta-analysis. Sci. World J., 2014: 624573. DOI: 10.1155/2014/624573

Sun, Y., K. Jin, J.T. Childs, L. Xie and X.O. Mao et al., 2004. Increased severity of cerebral ischemic injury in vascular endothelial growth factor-B-deficient mice. J. Cereb. Blood Flow Metab., 24: 1146-1152. PMID: 15529014

Sun, Y., K. Jin, L. Xie, J. Childs and X.O. Mao et al., 2003. VEGF-induced neuroprotection, neurogenesis and angiogenesis after focal cerebral ischemia. J. Clin. Invest, 111: 1843-1851. PMID: 12813020 
Sternberg, C.N., D.P. Petrylak, O. Sartor, J.A. Witjes and T. Demkow et al., 2009. Multinational, doubleblind, phase III study of prednisone and either satraplatin or placebo in patients with castraterefractory prostate cancer progressing after prior chemotherapy: The SPARC trial. J. Clin. Oncol., 27: 5431-5438. DOI: 10.1200/JCO.2008.20.1228

Tarkka, T., A. Sipola, T. Jamsa, Y. Soini ane S. YlaHerttuala et al., 2003. Adenoviral VEGF-A gene transfer induces angiogenesis and promotes bone formation in healing osseous tissues. J. Gene. Med., 5: 560-566. PMID: 12825195

Terman, B.I., M.E. Carrion, E. Kovacs, B.A. Rasmussen and R.L. Eddy et al., 1991. Identification of a new endothelial cell growth factor receptor tyrosine kinase. Oncogene, 6: 1677-1683. PMID: 1656371

Tie, Z., R. Bai, Z. Zhai, G. Zhang and H. Zhang et al., 2014. Single nucleotide polymorphisms in VEGF gene are associated with an increased risk of osteosarcoma. Int. J. Clin. Exp. Pathol., 7: 8143-8149. PMID: 25550863

Vajtr, D., D. Springer, L. Staněk, O. Benada and F. Samal et al., 2014. Pathomorphology of inflammatory response following traumatic brain injury, serum values of interleukins and gene polymorphisms. Soud. Lek., 59: 40-47. PMID: 25417641

Van Asten, F., M.M. Rovers, Y.T. Lechanteur, D. Smailhodzic and P.S. Muether et al., 2014. Predicting non-response to ranibizumab in patients with neovascular age-related macular degeneration. Ophthalmic Epidemiol., 21: 347-355. PMID: 25157998

Van Bruggen, N., H. Thibodeaux, J.T. Palmer, W.P. Lee and L. Fu et al., 1999. VEGF antagonism reduces edema formation and tissue damage after ischemia/reperfusion injury in the mouse brain. J. Clin. Invest, 104: 1613-1620.

DOI: $10.1172 / \mathrm{JCI} 8218$

Wang, J., G.S. Pang, S.S. Chong and C.G. Lee, 2012. SNP web resources and their potential applications in personalized medicine. Curr. Drug. Metab., 13: 978-990. PMID: 22591348

Wang, Y., V. Galvan, O. Gorostiza, M. Ataie and K. Jin et al., 2006. Vascular endothelial growth factor improves recovery of sensorimotor and cognitive deficits after focal cerebral ischemia in the rat. Brain Res., 1115: 186-193.

DOI: 10.1016/j.brainres.2006.07.060
Witte, L., D.J. Hicklin, Z. Zhu, B. Pytowski and H. Kotanides et al., 1998. Monoclonal antibodies targeting the VEGF receptor-2 (Flk1/KDR) as an anti-angiogenic therapeutic strategy. Cancer Metastasis Rev., 17: 155-161. PMID: 9770111

Xia, Y.P., B. Li, D. Hylton, M. Detmar and G.D. Yancopoulos et al., 2003. Transgenic delivery of VEGF to mouse skin leads to an inflammatory condition resembling human psoriasis. Blood, 102: 161-168. PMID: 12649136

Yuan, D., D. Yuan, X. Liu, S. Yuan and P. Xie et al., 2013. Genetic association with response to intravitreal ranibizumab for neovascular age-related macular degeneration in the Han Chinese population. Ophthalmologica, 230: 227-232. PMID: 24080590

Yuan, Q., X. Zuo and J. Jia, 2009. Association between promoter polymorphisms of vascular endothelial growth factor gene and sporadic Alzheimer's disease among Northern Chinese Han. Neurosci. Lett., 457: 133-136. PMID: 19429179

Zhang, Z.G., L. Zhang, Q. Jiang, R. Zhang and K. Davies et al., 2000. VEGF enhances angiogenesis and promotes blood-brain barrier leakage in the ischemic brain. J. Clin. Invest, 106: 829-838. PMID: 11018070

Zheng, X.R., S.S. Zhang, Y.J. Yang, F. Yin and X. Wang et al., 2010. Adenoviral vector-mediated transduction of VEGF improves neural functional recovery after hypoxia-ischemic brain damage in neonatal rats. Brain. Res. Bull., 81: 372-377. PMID: 19945513

Zidi, S., 2014. Relationship of common vascular endothelial growth factor polymorphisms and haplotypes with the risk of cervical cancer in Tunisians. Cytokine. DOI: $10.1016 /$ j.cyto.2014.11.009

Zhong, W., X. Wang, B. Pan and Z. Su, 2014. Association of vascular endothelial growth factor polymorphisms with clinical outcome of renal cell carcinoma patients. Tumor Biol., 35: 9839-9845. DOI: $10.1007 / \mathrm{s} 13277-014-2194-4$

Zhu, W., Y. Mao, Y. Zhao, L.F. Zhou and Y. Wang et al., 2005. Transplantation of vascular endothelial growth factor-transfected neural stem cells into the rat brain provides neuroprotection after transient focal cerebral ischemia. Neurosurgery, 57: 325-333. PMID: 16094163 